Article

\title{
Psychopaths Online: The Linguistic Traces of Psychopathy in Email, Text Messaging and Facebook
}

\author{
Jeffrey T. Hancock ${ }^{1, *}$, Michael Woodworth ${ }^{2}$ and Rachel Boochever ${ }^{3}$ \\ ${ }^{1}$ Department of Communication, Stanford University, Stanford, 94305, USA; E-Mail: jeff.hancock@stanford.edu \\ 2 Department of Psychology, University of British Columbia, Kelowna, V1V 1V7, Canada; E-Mail: michael.woodworth@ubc.ca \\ 3 Law School, Stanford University, Stanford, 94305, USA; E-Mail: rcb@stanford.edu \\ * Corresponding author
}

Submitted: 27 March 2018 | Accepted: 19 September 2018 | Published: 28 September 2018

\begin{abstract}
Individuals high in psychopathy are interpersonally manipulative, exhibit callous affect, and have criminal tendencies. The present study examines whether these attributes of psychopathy are correlated with linguistic patterns present in everyday online communication. Participants' emails, SMS messages, and Facebook messages were collected and analyzed in relation to their scores on the Self-Report Psychopathy Test III. The findings suggest that psychopathic tendencies leave a trace in online discourse, and that different forms of online media sometimes moderate the association between a linguistic dimension and psychopathy scores. Consistent with previous studies and the emotional and interpersonal deficits central to psychopathy, participants higher in psychopathy showed more evidence of psychological distancing, wrote less comprehensible discourse, and produced more interpersonally hostile language. The results reveal that linguistic traces of psychopathy can be detected in online communication, and that those with higher traits of psychopathy fail to modify their language use across media types.
\end{abstract}

\section{Keywords}

computer-mediated communication; email; Facebook; online media; psychopathy; text messaging

Issue

This article is part of a multidisciplinary issue of Media and Communication, edited by Epp Lauk (University of Jyväskylä, Finland) and Raul Reis (Emerson College, USA).

(C) 2018 by the authors; licensee Cogitatio (Lisbon, Portugal). This article is licensed under a Creative Commons Attribution 4.0 International License (CC BY).

\section{Introduction}

Language produced during communication can be indicative of personality traits, as well as emotional states, identity and cognitive style (Pennebaker, 2011; Pennebaker \& King, 1999; Pennebaker, Mehl, \& Niederhoffer, 2003). As Pennebaker (2011) describes, the words we use are like fingerprints; we all leave traces of ourselves behind in our words. A series of studies has examined the relationship between language use and the personality construct of psychopathy; more specifically, whether discourse patterns reflect psychopathic tendencies (Hancock, Woodworth, \& Porter, 2013). For example, people high in psychopathy show evidence of narcissism and psychological distancing in their language (Hancock et al., 2012).

While these results are important, they are limited in their generalizability due to narrow populations (e.g. imprisoned murderers) and limited discourse types (e.g., narratives elicited by researchers). Pennebaker (2011) notes that language styles are adaptive based on different situations. Thus, natural language, or language produced in the real world, would arguably provide better insight into one's personality. The increasing popularity of online communication, with its automatic storage capabilities, means that it is now easy to access language that has been produced naturally, enabling analysis of real world language. A good deal of research on 
online communication also suggests that these media affect how people communicate (e.g., Herring \& Androutsopoulos, 2015). This exploratory study seeks to examine the relationship between psychopathy and natural language produced in online communication. We also examine whether language produced in online communication is fundamentally different from language elicited in a laboratory setting.

\subsection{Attributes of Psychopathy}

The concept of psychopathy was first officially documented by Hervey Cleckley (1941/1976), who documented a subsection of his patients that displayed a dire lack of morality. The current conceptualization of a psychopath is of a manipulative, cunning and antisocial individual who, according to Hare (2006), comprise about $1 \%$ of the general population. Although people with psychopathic tendencies lack key emotional traits such as remorse and guilt, and generally present shallow affect, they have an uncanny ability to influence and deceive others. As mentioned above, previous studies have suggested that psychopaths' language is distinct from that of non-psychopaths, but additional studies are needed to examine the exact linguistic mechanisms that may be contributing to their success in interactions with others.

\subsection{Psychopathy and Language}

Several previous studies have used automatic linguistic analysis to examine the discourse of psychopaths convicted of murder. In one study (Hancock et al., 2013), psychopathic murderers, as opposed to non-psychopathic murderers, used more subordinating conjunctions (because, since, as, so that, etc.), evidencing of the use of more cause and effect statements, and indicating that the psychopaths' viewed their murders as more instrumental than non-psychopaths (see Woodworth \& Porter, 2002). Psychopathic murderers used more past tense words, fewer present tense words, more articles, and more concrete nouns than non-psychopathic murderers. The combination of these discourse patterns suggests that the psychopaths were more psychologically distanced from these incidents, likely reflecting their emotional deficits even when recounting a negative event as extreme as homicide. Psychopathic murderers also used twice as many content words relating to basic physiological needs, such as food, money, and shelter, but fewer words relating to higher interpersonal needs, such as family and love. This combination suggests that psychopaths are less concerned with meaningful relationships and more focused on basic needs and achievement of goals (see Woodworth \& Porter, 2002, and Porter \& Woodworth, 2007, for research considering the instrumental nature of psychopaths specifically for the offence of homicide). Finally, psychopaths produced more disfluencies, such as $u$ and um, when describing their murder than non-psychopaths, suggesting a less fluent and comprehensible narrative.
Other work has focused more on the language comprehension skills of psychopaths, which may have some bearing on our examination of their language production. For instance, Vaughn et al. (2011) found that juveniles high in psychopathy had poor reading achievement. Poor reading achievement may be reflective of the emotional deficits observed in psychopaths. Do people with high psychopathic tendencies also produce less readable language?

\subsection{Online Communication and Psychopathy}

The present study aims to expand the research discussed above by examining whether language produced during everyday online communication contains patterns associated with psychopathy. One of the most important attributes of online communication is that it leaves digital traces of messages, which allows researchers to examine real messages exchanged during the course of everyday communication. Compared to narratives elicited for an experiment, naturally produced language in online communication should be less formal, less prone to social desirability motivations, and reflect more realistic interpersonal dynamics. For instance, a number of recent studies suggest that private traits are predictable from records taken from online communication (e.g., Bachrach, Kosinski, Graepel, Kohli, \& Stillwell, 2012; Kosinski, Stillwell, \& Graepel, 2013). Given these attributes of online communication, we first expect that language in online communication will be different than experimentally elicited narratives, and second that more correlations between language dimensions and psychopathy will be observed in online communication than in elicited narratives.

With respect to the specific linguistic dimensions and attributes of psychopathy, we expect to find similar evidence of narcissistic tendencies and psychological distancing in online communication as found in previous studies (Hancock et al., 2012; Hancock et al., 2013; Sumner, Byers, Boochever, \& Park, 2012). Narcissism has been examined extensively in the context of social media (e.g., Carpenter, 2012; Davenport, Bergman, Bergman, \& Fearington, 2014), and based on these studies we predict that participants higher in psychopathy will use more first person singular pronouns, but fewer first person plural pronouns and fewer second person pronouns, and they should display increased psychological distancing in their language.

Reflecting the interpersonally manipulative characteristic of psychopathy, we expect that participants higher in psychopathy will use more cause and effect statements (Woodworth \& Porter, 2002). In particular, participants higher in psychopathy should use more subordinating conjunctions (because, so, etc.). We also expect to see evidence of psychopaths' increased focus on basic needs (food, drink, money, etc.) and reduced focus on higher level needs (spirituality, relationships, religion, etc.), consistent with Hancock et al. (2013). 
Given prior work showing that juveniles high in psychopathy have poor reading achievement (Vaughn et al., 2011), and that psychopaths tend to be more disfluent during speech (Hancock et al., 2013), we predict that participants higher in psychopathy will produce less comprehensible language as measured by a standard readability index.

We expect participants higher in psychopathy to produce more words associated with a hostile interpersonal demeanor, such as anger terms and swear words. Although this may seem contradictory considering their profound emotional deficits, another characteristic of psychopathy is poor behavioral control, which refers specifically to their quick temper in some situations. This poor behavioral control should be reflected in their language to a larger degree than participants scoring lower in psychopathy, specifically for conversations discussing a situation that was contentious. Indeed, recent work examining the dark triad in Twitter discourse (Sumner et al., 2012) found that users high in psychopathy and Machiavellianism used more swear words and more words associated with anger than other users. This finding was recently replicated by Bogolyubova, Panicheva, Tikhonov and Ivanov (2018), who found that male Facebook users scoring high in psychopathy sent more aggressive and insulting posts than users low in psychopathy. Thus, participants higher in psychopathy should use more words associated with anger and swear words in online communication.

Psychopathy can be assessed along several dimensions. For example, the Self-Report Psychopathy Scale III (SRP-III; Paulhus, Hemphill, \& Hare, 2012) conceptualizes the psychopathy with a four-factor structure, consistent with the Psychopathy Checklist-Revised (Mahmut, Menictas, Stevenson, \& Homewood, 2011). This measure of psychopathy includes: 1) Interpersonal Manipulation, the degree to which an individual finds it easy to manipulate or deceive others, 2) Criminal Tendencies, the degree to which an individual has been involved in illegal activities, 3) Erratic Lifestyle, the degree to which an individual is prepared to violate social norms and agreements, and 4) Callous Affect, the degree to which an individual displays a lack of empathy for others. An important research question is whether these four factors may be related to different language patterns in online communication. For example, hostile and aggressive language may be most associated with interpersonal manipulation, while psychological distancing might be more related to callous affect. How does language in online communication relate to these sub-factors of psychopathy?

Online communication is also not monolithic. The three types of online communication examined here may differentially reveal associations between language and psychopathy. As is now well-known in the communication and technology literature, different media types have unique sets of affordances that shape communication patterns (Clark \& Brennan, 1991; Whittaker, 2002). For example, SMS text messaging tends to be less formal than email, while Facebook messages tend to be more public than either SMS or email (Bazarova, 2012). How will these characteristics of each media affect the relationship between psychopathy and language?

Finally, our last research question was concerned with whether these language features could be used to classify people as scoring low or high on psychopathy. Prior work has found limited success in classifying Twitter users with machine learning techniques. For example, Sumner et al. (2012) found that the best models performed above chance, but that the models overall had poor accuracy when classifying individuals as scoring high in psychopathy. Here we examine whether having records from a variety of online communication and from elicited narratives can improve classification performance compared to the short messages found in Twitter discourse used in prior studies.

\section{Methods}

\subsection{Participants}

The participants in this study were 110 undergraduate students at a large US research university. The participants were recruited using the university's psychology experiment recruitment tool. They received course credit or $\$ 5$ in compensation for participating in this study. Of the 110 participants, 85 were female. Ages ranged from 18 to 24 years old, with a mean age of 20.2 years (std $=1.28)$.

\subsection{Materials}

We used the SRP-III (Paulhus et al., 2012) to measure psychopathic tendencies. The SRP-III is a reliable self-report measure of psychopathy that has demonstrated both convergent and divergent validity with a four-factor structure consistent with the Psychopathy Checklist-Revised (Mahmut et al., 2011). The SRP-III has been tested using both student samples and community samples, finding similar results (Williams, Nathanson, \& Paulhus, 2003; Williams, Paulhus, \& Hare, 2007; Mahmut et al., 2011). It consists of 64 questions, 16 questions each relating to four facets of psychopathy: callous affect (CA; e.g., "I am often rude to other people"), erratic lifestyle (ELS; e.g., "Rules are made to be broken"), interpersonal manipulation (IM; e.g., "I find it easy to manipulate people"), and criminal tendency (CT; e.g., "I have broken into a building or vehicle to steal or vandalize"). The higher the SRP-III score across these four factors the higher the psychopathic tendency for that participant.

The SRP-III was scored based on instructions from Paulhus et al.'s Manual for the Self-Report Psychopathy Scale. Each of the 64 questions was answered on a Likert scale from 1 (strongly disagree) to 5 (strongly agree). Of the 64 questions, 21 items were reverse-coded. All answers were summed to create a total SRP-III score, with a total possible range of 64 to 320 , and a possible range of 
16 to 80 for each of the four facets. For the present sample, the SRP-III mean total was $143.1(S D=27.4)$, with a minimum score of 82 and a maximum of 215.

For the elicited narratives, participants were asked to write two short stories, one about a positive event in their life, and one about a negative event in their life. They were asked to write stories of approximately 100 words. The negative elicited stories on average were 116 words ( $S D=36.3$ ) while the positive stories were 110.0 words $(S D=33.9)$. For the online communication messages, the average for text messages was 140.8 ( $S D=78.5$ ) words, for Facebook messages 142.5 ( $S D=96.1$ ) words, and for email was 700.2 $(S D=397.1)$ words.

\subsection{Procedure}

This study was conducted in the form of an online web survey via Qualtrix. After providing informed consent, participants were asked to complete the SRP-III and submit four types of language samples: 1) a short positive story and a short negative story, each about 100 words, which we refer to as "elicited narratives", 2) their twenty most recently sent SMS messages, 3) their twenty most recent sent emails, and 4) five each of their most recent Facebook status updates, private messages, and wall posts. For the elicited narratives, participants typed the stories into a text box. For the SMS messages, emails, and Facebook messages, collectively called "online communication" samples, participants transcribed their SMS messages from their mobile phone into the survey, and for the email and Facebook samples participants simply copied them from a web browser into the survey form. Participants were also asked demographic questions at the end of the survey (age and gender). Once they completed the survey they received debriefing information and remuneration.

\subsection{Text Analysis}

All language samples were converted into word documents and analyzed using the text analysis program Linguistic Inquiry and Word Count (LIWC; Pennebaker, Boothe, \& Francis, 2007). LIWC identifies and categorizes words based on linguistic dimensions, psychological constructs, personal concern categories, and paralinguistic dimensions, among other output variables (Hancock et al., 2012). Based on a dictionary of almost 4,500 words and word stems, LIWC counts the amount of words in each category, and divides the sum by the word count. This gives the percentage each category represents of the total word count, normalizing for verbosity. LIWC has been validated in a large number and variety of psychology and communication studies (Pennebaker, 2011).

To analyze the attributes of psychological distancing, basic needs, high-level needs, and readability we used algorithms of combined multiple standardized linguistic variables from LIWC. For psychological distancing, we used Chung \& Pennebaker's (2007) algorithm, a combination of: six letter words, articles, past tense, and the inverse of first person singular pronouns, present tense and discrepancy words. For basic and higher level needs, we used sets of words identified in previous studies and mapped on to the LIWC dictionary (Hancock et al., 2012; Woodworth \& Porter, 2002): basic needs include sex, money, leisure, achievement, work, health, and biology in the LIWC dictionary; higher level needs include family, religion, positive emotion, social, friends, and the inverse of death. Lastly, we based readability on an approximation of the Flesch-Kincaid readability test (Kincaid, Fishburn, Rogers Jr., \& Chissom, 1975), calculated by multiplying negative one by six letter words, adding words per sentence, subtracting the amount of words recognized by the LIWC dictionary, and adding three. Finally, we included word categories in LIWC that reflect aggressive discourse, including swear words (e.g., "asshole") and anger terms (e.g., "dammit").

\section{Results}

\subsection{Data Analysis}

Our analytic approach involved two steps. First we used linear mixed models to test for language differences between discourse type (online communication vs. elicited narratives), with the two discourse types nested within each participant to account for non-independence between the discourse samples. This analysis revealed significant differences between online communication and elicited narratives for virtually all of the language dimensions. Thus, in the second step of the analysis we examined online communication and elicited narratives separately. In this second step we calculated the bivariate correlations between each language variable and the SRP-III factors and used linear mixed models to examine possible interactions with media type (email, SMS text messaging and Facebook) for online communication and valence (positive vs. negative) for elicited narratives.

\subsection{Discourse Patterns in Online Communication versus Elicited Narratives}

Our first research question examined whether the language patterns in online communication were different from those observed in elicited narratives along the primary dimensions of interest. We combined the email, Facebook, and SMS transcripts to create an online Communication Index for each language variable, and we combined the positive and negative narratives to create an Elicited Narrative Index.

As can be seen in Table 1, significant differences between online communication and elicited narrative discourse emerged for most language variables, including pronouns, verb tense, and emotions. In elicited narratives, participants wrote more about themselves, wrote more about past events, and used fewer emotion words 
Table 1. Mean $(S D)$ discourse features across online communication and elicited narratives as a percentage of total words.

\begin{tabular}{|c|c|c|c|c|c|c|c|}
\hline & & \multicolumn{2}{|c|}{ Online Communication } & \multicolumn{2}{|c|}{ Elicited Narratives } & \multirow[b]{2}{*}{$F(1,436)$} & \multirow[b]{2}{*}{$P$} \\
\hline & & $M$ & $S E$ & $M$ & $S E$ & & \\
\hline \multirow[t]{3}{*}{ Pronouns } & 1 & $6.61 \%$ & $.19 \%$ & $9.47 \%$ & $.22 \%$ & 126.9 & $<.001$ \\
\hline & We & 1.03 & .09 & 1.21 & .10 & 1.95 & .14 \\
\hline & You & 3.86 & .11 & .05 & .13 & 623.4 & $<.001$ \\
\hline \multirow[t]{2}{*}{ Tense } & Past & 2.64 & .14 & 8.95 & .17 & 999.5 & $<.001$ \\
\hline & Present & 12.41 & .21 & 3.31 & .24 & 1012.7 & $<.001$ \\
\hline \multirow[t]{4}{*}{ Emotion } & Positive & 7.24 & .21 & 3.88 & .25 & 112.3 & $<.001$ \\
\hline & Negative & 1.67 & .11 & 2.25 & .13 & 11.4 & .001 \\
\hline & Anger & .47 & .05 & .37 & .06 & 1.7 & .19 \\
\hline & Swear & .25 & .03 & .02 & .04 & 24.1 & $<.001$ \\
\hline
\end{tabular}

than in their online discourse. In general, these results suggest that the elicited narratives were focused more on the participants' actions in the past, and despite being asked to write about positive and negative experiences, these stories were overall less emotional than their everyday online discourse. It is also important to note that participants used more words relating to anger and more swear words in online communication than in elicited narratives, indicating that language use in online communication is more colloquial and informal than what participants write in a laboratory setting. These data support our expectations that discourse patterns in online communication differ substantially from elicited narratives.

\subsection{Psychopathy Scores and Online Communication}

Our primary question of interest was how online communication predicts psychopathy scores. Table 2 describes the simple bivariate correlations for the language dimensions from the combined Online Communication Index and psychopathy scores including the SRP-III sub-factors. To compare across the three media types (SMS text mes- saging, email, Facebook) we used linear mixed models to account for the non-independence of the writing samples for each participant. A mixed model was created for each language variable, with media type (email, SMS, Facebook) nested within participant, to predict the overall SRP-III psychopathy score. For each hypothesis, the mixed model tested the effect of the language variable on psychopathy scores and the interaction between the media type and the language variable (whether the association between psychopathy scores and the language variable was different across media type).

\subsubsection{Narcissistic Tendencies}

We expected that participants higher in psychopathy would exhibit narcissistic tendencies in the pattern of their pronoun use, with increased focus on self and decreased focus on others. This hypothesis was partially supported. As can be seen in Table 2, second person pronoun pronouns were negatively correlated with overall psychopathy scores, suggesting that more psychopathic individuals referred less often to other people in their conversations. This effect was driven by negative associ-

Table 2. Pearson bivariate 2-tailed correlations between SRP-III scores and selected linguistic factors in online communication.

\begin{tabular}{|c|c|c|c|c|c|}
\hline & $\begin{array}{l}\text { SRP-III } \\
\text { Total }\end{array}$ & $\begin{array}{l}\text { Interpersonal } \\
\text { Manipulation }\end{array}$ & $\begin{array}{l}\text { Callous } \\
\text { Affect }\end{array}$ & $\begin{array}{c}\text { Erratic } \\
\text { Life Style }\end{array}$ & $\begin{array}{l}\text { Criminal } \\
\text { Tendency }\end{array}$ \\
\hline 1 & .05 & .01 & .03 & .09 & .04 \\
\hline We & -.02 & .01 & -.02 & -.03 & -.01 \\
\hline You & $-.24^{*}$ & -.17 & $-.21 *$ & $-.28 * *$ & -.12 \\
\hline Psychological Distancing & $.19 *$ & .11 & $.24^{*}$ & $.23^{*}$ & .05 \\
\hline Conjunctions & -.12 & -.14 & $-.19 *$ & .10 & -.18 \\
\hline Basic Needs & -.02 & -.15 & -.03 & .12 & -.01 \\
\hline Higher Needs & -.12 & -.14 & -.09 & -.08 & -.08 \\
\hline Readability & $-.32 * *$ & $-.24 *$ & $-.22 *$ & $-.34 * *$ & $-.23 *$ \\
\hline Anger & $.22^{*}$ & $.23^{*}$ & .13 & .18 & .17 \\
\hline Swear & $.31 * *$ & $.30 * *$ & $.23^{*}$ & $.21^{*}$ & $.25^{* *}$ \\
\hline
\end{tabular}

Notes: ${ }^{*}$ Correlation is significant at the 0.05 level (2-tailed); ${ }^{* *}$ Correlation is significant at the 0.01 level (2-tailed). 
ations with the Callous Affect and Erratic Life Style factors, indicating that participants that scored higher on these two factors were less likely to refer to their communication partner (e.g., you). The mixed model analysis revealed that the inverse relationship between second person pronoun use and psychopathy scores was not affected by the media type, $F(1,322)<1$. Thus, increased levels of psychopathy were associated with reduced second person pronoun use across all three forms of online communication.

First person singular $(I)$ and plural (we), however, which were expected to correlate positively with psychopathy scores, were not associated with the SRP-III scores (see Table 2). Thus, while participants with higher psychopathy scores referred to other people less in their online conversations, suggesting reduced attention towards their conversation partner, they did not also explicitly focus more on themselves.

\subsubsection{Psychological Distancing}

We expected that participants higher in psychopathy would use more psychological distancing. This hypothesis was supported in the correlation analysis. Psychological distancing was negatively associated with overall psychopathy scores. This effect was driven by negative correlations with Callous Affect and Erratic Lifestyle, suggesting that participants scoring higher on these factors wrote with more psychological distance in their online communication.

The linear mixed model analysis produced a significant interaction, however, between media type and psychological distancing, $F(1,321)=3.42, p<.034$. This interaction revealed that the association between psychological distancing was most evident in email $(b=.27$, $p<.005)$, followed by language from Facebook $(b=.19$, $p<.05)$, but was not significant in Facebook posts $(b=-.05, n s)$. These data suggest that the type of online communication plays an important role in how the psychological distancing associated with psychopathy is expressed in language use.

\subsubsection{Subordinating Conjunctions}

We expected that participants scoring high in psychopathy would use more conjunctions given prior work indicating that psychopaths tend to view the world instrumentally. This hypothesis was not supported. In fact, in contrast with our expectations, participants high in the callous affect factor of psychopathy used fewer subordinating conjunctions. We did not explore this unexpected correlation further.

\subsubsection{Basic vs. High-Level Needs}

Our hypothesis that participants high in psychopathy would focus more on basic needs and less on higher level needs was not supported. No effects were observed between psychopathy scores and either basic or higher level needs in online discourse.

\subsubsection{Readability}

Readability was negatively correlated with total SRP-III scores and all four sub-factors in online discourse. The mixed model analysis, however, produced a marginally significant interaction between media type and readability in predicting psychopathy, $F(1,320)=2.67, p=.07$. The interaction revealed that the association between readability and psychopathy was only evident in email discourse $(b=-.28, p<.003)$, and not in Facebook or SMS text messaging. One possible reason is that the range of readability of Facebook and SMS text messages is constrained by word length limitations (e.g., SMS text messaging is typically 140 characters).

\subsubsection{Hostile Interpersonal Style}

Our hypothesis that participants scoring higher in psychopathy would use more words associated with anger and swear words was supported. The frequency of swear words correlated with the total psychopathy score and each sub-factor, and anger words correlated with the total score and interpersonal manipulation. The linear mixed model analysis revealed no interaction effect with media type for either anger words or swear words, suggesting that this hostile interpersonal style is evident across the three media types for participants scoring highly on the SRP-III.

\subsection{Psychopathy Scores and Elicited Narratives}

The same analysis was conducted on the elicited narratives. The bivariate correlations are reported in Table 3. To compare across the valence of the elicited narratives (positive vs. negative) we again used linear mixed models to account for the non-independence of the writing samples for each participant. A mixed model was created for each language variable, with narrative valence nested within participant, to predict the overall SRP-III psychopathy score.

Unlike the frequent associations between psychopathy scores and online communication, the language from the elicited narratives were correlated with psychopathy scores along only two dimensions. Consistent with our hypothesis, participants scoring higher in psychopathy wrote their narratives with more words related to basic needs, and this association was primarily driven by scores on criminal tendency. Also as expected, participants scoring higher in psychopathy wrote narratives that were lower in readability, which was driven by the callous affect and criminal tendency factors. The mixed model analysis revealed that there were no interaction effects between media type and language dimension, suggesting the basic needs and readability effects were the same for positive and negative narratives. 
Table 3. Pearson bivariate 2-tailed correlations between SRP-III scores and selected linguistic factors in elicited narratives.

\begin{tabular}{|c|c|c|c|c|c|}
\hline & $\begin{array}{l}\text { SRP-III } \\
\text { Total }\end{array}$ & $\begin{array}{l}\text { Interpersonal } \\
\text { Manipulation }\end{array}$ & $\begin{array}{l}\text { Callous } \\
\text { Affect }\end{array}$ & $\begin{array}{c}\text { Erratic } \\
\text { Life Style }\end{array}$ & $\begin{array}{l}\text { Criminal } \\
\text { Tendency }\end{array}$ \\
\hline 1 & .01 & .05 & .04 & -.03 & -.04 \\
\hline We & .03 & .05 & -.04 & .06 & .04 \\
\hline You & -.09 & -.01 & -.08 & -.11 & -.11 \\
\hline Psychological Distancing & .08 & .06 & .09 & .06 & . 07 \\
\hline Conjunctions & -.07 & -.03 & -.07 & -.05 & -.07 \\
\hline Basic Needs & $.14 *$ & -.04 & .07 & .13 & $.22 * *$ \\
\hline High-Level Needs & -.04 & -.03 & -.02 & .01 & -.07 \\
\hline Readability & $-.15^{*}$ & -.08 & $-.15^{*}$ & -.09 & $-.17^{*}$ \\
\hline Anger & -.03 & -.02 & -.02 & -.03 & -.04 \\
\hline Swear & -.04 & .01 & -.01 & -.13 & .02 \\
\hline
\end{tabular}

Notes: * Correlation is significant at the 0.05 level (2-tailed); ${ }^{* *}$ Correlation is significant at the 0.01 level (2-tailed).

\subsection{Classifying Low versus High on the SRP-III.}

Our last question was concerned with how the language features in online communication could be used to classify participants as scoring high versus low in psychopathy. To address this question we conducted a quartile split on the SRP-III data, with participants scoring below 123 on the scale in the bottom quartile (Low Psychopathy) and those scoring above 162 in the top quartile (High Psychopathy). A logistic regression predicting Low vs. High Psychopathy was constructed by entering each of the language features that displayed bivariate correlations with scores on the SRP-III (see Table 2), including second person pronouns, anger terms, swear words, readability and psychological distancing. The regression was significant, $\chi^{2}(5)=42.32, p<.001$, and accounted for approximately $36.7 \%$ of the variance. The classification accuracy was $78.9 \%$, with 16 of the 22 high scorers correctly identified and 17 of the 23 low scorers correctly identified.

\section{Discussion}

The goal of this study was two-fold: 1) to examine discourse patterns associated with psychopathy in two different communication contexts, online communication and elicited narratives, and 2) to examine how psychopathy is expressed differently across several types of online communication. Language collected from archived emails, SMS text messages, and Facebook messages revealed that language produced in online communication was significantly different than language elicited for the purpose of a study in terms of pronoun use, verb tense, and emotion terms. In addition, more correlations between various components of psychopathy were found with language produced naturally in online communication than in the elicited narratives, suggesting online discourse is a rich source of communication that can reveal key aspects of the self.
Several hypotheses about the association between the SRP-III psychopathy scores and linguistic patterns in online communication were supported. In online communication participants higher in psychopathy referred less often to their conversation partner, used more psychological distancing, produced less comprehensible text, and used more interpersonally hostile language, such as anger and swear words. However, participants higher in psychopathy did not focus more on basic needs or less on higher level needs in online communication. In contrast, a positive correlation with basic needs and psychopathy scores was observed in the elicited narratives, one of the few instances where associations emerged in the narratives but not in online communication. For instance, narratives are more likely to provide insight for why a person performed an action (e.g., "At the birthday party I just wanted to eat the cake because I was starving"). If this is the case then research examining the role that motivations, such as basic needs, play in psychopathy should focus on elicited narratives rather than naturally produced communication. Finally, psychopathy scores were not correlated with conjunctions, suggesting that participants higher in psychopathy did not use more cause and effect statements.

Despite important differences between the criminal and student samples, evidence of psychological distancing in the current study demonstrates that some aspects of Hancock et al.'s (2013) findings with criminal psychopaths may also apply to a more general population. Psychological distancing suggests that psychopaths do not emotionally connect with what they are saying and that they are either detached from their language or use the same type of language to refer to both emotional and non-emotional concepts. This was particularly the case for individuals scoring high on Callous Affect and Erratic Lifestyle, which both suggest deficiencies in social and interpersonal functioning.

Additionally, it is important to understand language production in relation to the reading comprehension 
deficits observed with people with psychopathic tendencies (Vaughn et al., 2011). The finding that participants higher in psychopathy produced less comprehensible text in both online communication and elicited narratives is consistent with previous studies, such as Brinkley, Newman, Harpur and Johnson (1999), and demonstrates for the first time that some of the speech difficulties found in previous studies, such as lack of cohesion or increased speech disfluencies, are also apparent in textbased online communication contexts in the form of reduced readability.

Evidence of increased anger and swearing in online communication is consistent with psychopath's proclivity for interpersonal manipulation, as well as the poor behavioral controls associated with callous affect, specifically for anger. For example, one participant who scored a 200 on the SRP-III (higher than two standard deviations above the mean score) wrote in an email: "I do not wish to talk to you anymore about anything ever again. I'm glad that this is over because talking to you is like sticking a spoon in my ass". The same participant had the following Facebook status updates: "Dead", "Bored", "Tired", "Fighting with her again", and "Hate everyone". While this person may be an outlier given their very high SRPIII score, these aggressive and insulting posts are consistent with prior research finding that people scoring high on psychopathy tend to send messages with more negative emotion terms and swear words (Bogolyubova et al., 2018; Sumner et al., 2012).

It is also important to note that anger and swearing are significantly correlated with SRP-III scores in online communication, but not in the elicited narratives. Psychopaths are known for their impulsivity and their increased usage of swear words and anger words could indicate their reduced ability to control the type of language they are producing (e.g., negative) in natural discourse. The finding that they are even less able to do this in online communication contexts warrants further investigation. For instance, we found that the swear words and anger terms were correlated with psychopathy scores in one-to-one forms of communication, including email and text messaging, but not in broadcast forms of communication, such as posting on Facebook. These data suggest that participants higher in psychopathy managed to keep their hostile language limited to direct communication and avoided using it in more public online communication. More work is required to understand how the features of online communication specifically trigger or exacerbate a psychopath's impulsive nature, as may be the case for online trolls (Lopes \& Yu, 2017).

Despite the intriguing findings outlined above, this study is limited by both the small sample size, $N=110$, and the small size of the language samples collected. A larger, more diverse group of participants and a greater number of language samples could produce different results. Nonetheless, these data provided sufficient power to observe predicted results along many of the hypothe- ses. An important direction to build on this work, however, is attempting to include more individuals that score highly on the SRP-III. Psychopathy scores were primarily in the low and moderate ranges, consistent with the rates of psychopathy in general community samples, with few reaching the actual cut-off denoting psychopathy. The fact that such differences were found across the range of psychopathy scores emphasizes the importance of our findings considering the truncated range of psychopathy in the current sample.

\section{Conclusion}

This study extended prior work examining the discourse patterns of psychopaths and non-psychopaths by examining different forms of online discourse. Our findings, across three types of online communication (email, Facebook and SMS text messaging) support previous research, showing that discourse patterns of participants' higher in psychopathy showed evidence of narcissism, psychological distancing, produced less comprehensible text, and used more words indicative of an interpersonally hostile style, including more anger and swear words. These results were more pronounced in online discourse than in elicited narrative discourse, suggesting that real world discourse is more revealing of psychopathic tendencies. There may be features unique to online communication that afford a better opportunity to spot these linguistic traces of psychopathy, or online interactions that are more likely to trigger or prompt these differences. Regardless, our results reinforce the theory that individual personality characteristics, such as psychopathic tendencies, can be reflected in discourse patterns found in online communication.

\section{Acknowledgments}

This research was funded in part by a grant from SSHRC awarded to the second author. The authors also acknowledge Sunny Liu for comments on a previous draft.

\section{Conflict of Interests}

The authors declare no conflict of interests.

\section{References}

Bachrach, Y., Kosinski, M., Graepel, T., Kohli, P., \& Stillwell, D. (2012). Personality and patterns of Facebook usage. In Proceedings of Web Science'12 (pp. 24-32). Evanston, IL: ACM.

Bazarova, N. N. (2012). Public intimacy: Disclosure interpretation and social judgments on Facebook. Journal of Communication, 62(5), 815-832.

Bogolyubova, O., Panicheva, P., Tikhonov, R., Ivanov, V., \& Ledovaya, Y. (2018). Dark personalities on Facebook: Harmful online behaviors and language. Computers in Human Behavior, 78, 151-159. 
Brinkley, C. A., Newman, J. P., Harpur, T. J., \& Johnson, M. M. (1999). Cohesion in texts produced by psychopathic and non-psychopathic criminal inmates. Personality and Individual Differences, 26(5), 873-885.

Carpenter, C. J. (2012). Narcissism on Facebook: Selfpromotional and anti-social behavior. Personality and Individual Differences, 52(4), 482-486.

Chung, C. K., \& Pennebaker, J. W. (2007). The psychological function of function words. In K. Fiedler (Ed.), Social communication: Frontiers of social psychology (pp. 343-359). New York, NY: Psychology Press.

Clark, H. H., \& Brennan, S. E. (1991). Grounding in communication. In L. B. Resnick, J. M. Levine, \& S. D. Teasley (Eds.), Perspectives on socially shared cognition (pp. 127-149). Washington, DC: American Psychological Association.

Cleckley, H. (1976). The mask of sanity (5th ed.). St. Louis, MO: Mosby. (Original work published 1941)

Davenport, S., Bergman, S. M., Bergman, J. Z., \& Fearrington, M. E. (2014). Twitter versus Facebook: Exploring the role of narcissism in the motives and usage of different social media platforms. Computers in Human Behavior, 32, 212-220.

Hancock, J. T., Woodworth, M., \& Porter, S. (2013). Hungry like the wolf: A word pattern analysis of the language of psychopaths. Legal and Criminological Psychology, 18(1), 102-114.

Herring, S. C., \& Androutsopoulos, J. (2015). Computermediated discourse 2.0. In D. Tannen, H. E. Hamilton, \& D. Schiffrin (Eds.), The handbook of discourse analysis (2nd ed., pp. 127-151). West Sussex: John Wiley \& Sons.

Hare, R. D. (2006). Psychopathy: A clinical and forensic overview. Psychiatric Clinics of North America, 29(3), 709-724.

Kincaid, J. P., Fishburn, R. P., Rogers Jr., R. L., \& Chissom, B. S. (1975). Derivation of new readability formulas for Navy enlisted personnel (Research Branch Report, 8-75). Naval Air Station Memphis, Millington, Tennessee.

Kosinski, M., Stillwell, D., \& Graepel, T. (2013). Private traits and attributes are predictable from digital records of human behavior. Proceedings of the $\mathrm{Na}$ tional Academy of Science, 110(15), 5802-5805.

Lopes, B., \& Yu, H. (2017). Who do you troll and why: An investigation into the relationship between the dark triad personalities and online trolling behaviours towards popular and less popular Facebook profiles. Computers in Human Behavior, 77, 69-76.

Mahmut, M. K., Menictas, C., Stevenson, R. J., \& Home- wood, J. (2011). Validating the factor structure of the self-report psychopathy scale in a community sample. Psychological Assessment, 23(3), 670-678.

Paulhus, D. L., Hemphill, J. D., \& Hare, R. D. (2012). Manual for the Self-Report Psychopathy Scale. Toronto: Multi-Health Systems.

Pennebaker, J. W. (2011). The secret life of pronouns: What our words say about us. New York, NY: Bloomsbury Press.

Pennebaker, J. W., Boothe, R. J., \& Francis, M. E. (2007). Linguistic inquiry and word count. LIWC [Computer software]. Austin, TX: liwc. net.

Pennebaker, J. W., \& King, L. A. (1999). Linguistic styles: Language use as an individual difference. Journal of Personality and Social Psychology, 77(6), 1296-1312.

Pennebaker, J. W., Mehl, M. R., \& Niederhoffer, K. G. (2003). Psychological aspects of natural language use: Our words, our selves. Annual Review of Psychology, 54(1), 547-577.

Porter, S., \& Woodworth, M. (2007). “I'm sorry I did it...but he started it": A comparison of the official and self-reported homicide descriptions of psychopaths and non-psychopaths. Law and Human Behavior, 31(1), 91-107.

Sumner, C., Byers, A., Boochever, R., \& Park, G. J. (2012). Predicting dark triad personality traits from twitter usage and a linguistic analysis of tweets. In Machine learning and applications (icmla), 2012 11th international conference (Vol. 2, pp. 386-393). IEEE.

Vaughn, M. G., DeLisi, M., Beaver, K. M., Wexler, J., Barth, A., \& Fletcher, J. (2011). Juvenile psychopathy personality traits are associated with poor reading achievement. Psychiatric Quarterly, 82(3), 177-190.

Whittaker, S. (2002). Theories and methods in mediated communication. In A. Graesser, M. Gernsbacher, \& S. Goldman, (Eds.), The handbook of discourse processes (pp. 243-286). Hillsdale, NJ: Erlbaum.

Williams, K. M., Nathanson, C., \& Paulhus, D. L. (2003). Structure and validity of the Self-Report Psychopathy Scale-III in normal populations. Presented at the 111th annual convention of the American Psychological Association. Toronto, Canada.

Williams, K. M., Paulhus, D. L., \& Hare, R. D. (2007). Capturing the four-factor structure of psychopathy in college students via self-report. Journal of Personality Assessment, 88(2), 205-219.

Woodworth, M., \& Porter, S. (2002). In cold blood: Characteristics of criminal homicides as a function of psychopathy. Journal of Abnormal Psychology, 111(3), 436-445.

\section{About the Authors}

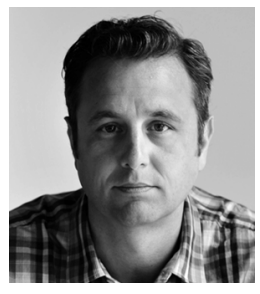

Jeffrey T. Hancock is a Professor in the Department of Communication at Stanford University. His work is concerned with how social media affect psychological and interpersonal processes, with a particular emphasis on understanding how language can reveal psychological and social dynamics. 

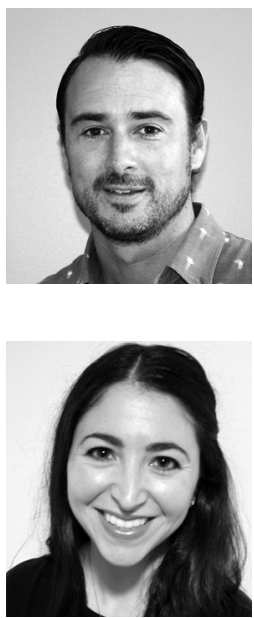

Michael Woodworth is a Professor in the Department of Psychology at University of British Columbia, Okanagan. He is a clinical psychologist with research interests in forensic psychology, psychopathy, deception detection, mental health social media and computer-mediated communication research.

Rachel Boochever graduated from Cornell University with a BS in Communication with distinction in research. She graduated from Stanford Law School in 2018 and is an Associate at Wilson Sonsini Goodrich \& Rosati in Palo Alto. 